\title{
CONEXÕES ENTRE CAMPO E CIDADE NA AMAZÔNIA PARAENSE: AGRICULTORES FAMILIARES E SUAS RELAÇÕES COM A CIDADE DE MARABÁ-PA ${ }^{1}$
}

\author{
Danielle Wagner ${ }^{2}$ \\ William Santos de Assis ${ }^{3}$
}

\begin{abstract}
Resumo
O objetivo deste trabalho foi identificar e discutir as relações estabelecidas pelos agricultores familiares do entorno da vila Santa Fé com a cidade de Marabá-PA. Os dados empíricos foram coligidos a partir de pesquisa de campo realizada em 2010 junto a agricultores residentes nesta localidade. A categoria analítica campo-cidade foi tomada como referência para a discussão e análise. Os resultados mostraram, num contexto de transformações aceleradas, a emergência de novos espaços, como vilas e assentamentos rurais, de novas atividades produtivas e de novas relações que interconectam campo e cidade através da circulação dos indivíduos em ambos os espaços. Por isso, a "rua", termo utilizado pelos agricultores para designar a cidade, representa o local de acesso a determinados serviços não disponíveis no espaço visto como rural, caracterizando a relação campo-cidade como resultante de uma teia de relações construídas por laços econômicos, político-administrativos e afetivos. Apesar de haver mudanças na relação campo-cidade, no contexto estudado não se observa a predominância de características que designam "novas" ruralidades.
\end{abstract}

Palavras-chave: Relação campo-cidade; Relações Sociais; Núcleos de povoamento; Espaço Rural.

\section{CONNECTIONS BETWEEN COUNTRY AND CITY SIDE IN THE PARA AMAZON: FAMILY FARMERS AND THEIR RELATIONSHIP WITH THE CITY OF MARABÁ-PA}

\footnotetext{
Abstract

The objective of this paper was to identify and discuss the relationships established by the family farmers from the around of the village Santa Fé with the municipality Marabá - PA. The empirical data were collected from a camp research realized on 2010 with

${ }^{1}$ Este artigo deriva da dissertação de mestrado da autora, orientada pelo coautor. O trabalho de pesquisa teve apoio financeiro da Agence Nationale de la Recherche de Francia através do programa SYSTERRA, referência ANR-09-STRA-04

${ }^{2}$ Engenheira Agronôma (UFPA). Mestrado em Agriculturas Familiares e Desenvolvimento Sustentável (PGAA/UFPA). Doutoranda em Desenvolvimento Rural (PGDR/UFRGS). Prof. da Universidade Federal do Oeste do Pará (UFOPA). Email: danicawagner@yahoo.com.br

${ }^{3}$ Graduado em Agronomia (UFPA). Mestrado em Agriculturas Familiares e Desenvolvimento (UFPA). Doutorado em Ciências Sociais em Desenvolvimento, Agricultura e Sociedade (CPDA/UFRRJ). Prof. Adjunto da Universidade Federal do Pará (UFPA). Email: williamassis@ufpa.br
} 
the farmers living on this area. The analytical category country - town was grounded as a reference for the discussion and analysis. The results show that, in a context of rapid changes, the emergence of new spaces such as villages and rural settlements, new productive activities and new relationships that interconnect the country and the town through the circulation from the people in the both spaces. Therefore, the "rua" (street, way), a term used by the farmers to designate the town, represents the site for access to certain services not available in space seen as rural, characterizing the relationship between field-city as a result of a web of relationships built on economic, political-administrative and affective ties. Although there are changes in the rural-urban relationship, in the context studied we didn't observe the predominance of characteristics that describe "new" ruralities.

Key-words: Relationship Country- town, Social Relationship, Population centers, Rural space.

\section{INTRODUÇÃO}

Os estudos recentes sobre as transformações em curso no campo brasileiro têm dado aporte para o entendimento do papel deste e das cidades na dinâmica territorial ${ }^{1}$. Considerando os processos a partir dos quais são originados, há diversas formas de identificar, investigar e interpretar os mecanismos condicionantes das transformações. Nesse sentido, a relação campo-cidade tem sido utilizada como categoria analítica a partir da qual pesquisadores discutem os efeitos da industrialização e da modernização na sociedade, demonstrando como campo e cidade têm sido reconfigurados e ressignificados ao longo das décadas.

No entanto, a diversidade social, econômica e cultural das regiões brasileiras sugere cautela nos estudos sobre o tema campo e cidade, principalmente quando esses abordam as inter-relações existentes entre espaços e modos de vida. Tradicionalmente o campo tem sido visto como o lugar da produção agropecuária, fornecedor de mão de obra para os centros urbanos, matéria-prima para diferentes atividades e consumidor de produtos oriundos das cidades (ABRAMOVAY, 2009; MARAFON, 2011). Recentemente, atribuem-se de forma crescente, características como a produção não agrícola, bem como as industriais, o turismo de observação e aventura e moradia (MARAFON, 2011). Como observam Carneiro (1998; 2002), Abramovay (2009) e Marafon (2011), crescem também postos de trabalhos como caseiros, diaristas, jardineiros, dentre outros. Nesse contexto, a cidade passa a ser também o local de trabalho de muitos moradores do campo. A questão que se coloca é saber se esse comportamento é observável em todo território brasileiro. Cabe aqui indagar: o que acontece em uma região com fortes características de fronteira agrícola onde as cidades estão em expansão?

No sudeste paraense, a dinâmica agrária é marcada fortemente por mudanças nas formas de exploração do meio natural, da organização social e dos sistemas de troca em torno dos elementos naturais e dos serviços disponíveis nos núcleos de povoamento formados e expandidos ao longo desses processos como as vilas e as cidades.

\footnotetext{
${ }^{1}$ Como exemplo desses estudos podem ser citados os trabalhos de Graziano da Silva (1997), Carneiro (1998; 2002), Wanderley (2001; 2009a), Abramovay (2009) e Marafon (2011).
} 
Considerando a importância que tais núcleos supostamente apresentam na conformação da agricultura familiar regional, e a influência que este grupo social tem na estruturação desses núcleos, através deste trabalho, objetivamos identificar e discutir as relações estabelecidas pelos agricultores familiares com a cidade sede do município de Marabá. A partir da situação empírica, o estudo contribui com as reflexões sobre as transformações pelas quais tem passado a região sudeste do Pará, e sobre a relação campo-cidade no cotidiano dos agricultores familiares dessa parte da Amazônia.

O texto segue estruturado em quatro seções além desta introdução. Na primeira fazemos uma breve discussão sobre a categoria analítica campo-cidade no intuito de melhor situar o tema no contexto do trabalho. Na segunda seção, apresentamos os procedimentos metodológicos da pesquisa de campo. Em seguida, ao discutirmos os resultados, contextualizamos o surgimento dos núcleos de povoamento na região sudeste paraense e analisamos as relações que os agricultores familiares estabelecem com esses núcleos e a cidade de Marabá. E, finalizando o texto, apresentamos as considerações finais.

\section{CAMPO E CIDADE COMO CATEGORIAS JUSTAPOSTAS}

A relação campo-cidade constitui-se como objeto de estudo em contextos onde a industrialização e o efeito da urbanização são considerados determinantes na transformação do espaço rural. Os pesquisadores afiliados à vertente marxista, tais como Lefebvre (1974), Sorokin, Zimmerman e Galpin (1981), Saraceno (1996), Graziano da Silva (1997), Santos (2000) e Wanderley (2001), tratam a relação campocidade como resultado da divisão social do trabalho, ocasionada pela expansão do capitalismo e das transformações desencadeadas pelo processo de industrialização.

No Brasil, esse debate surgiu na década de 1970 conectado à visão paradigmática que distingue campo de cidade. A partir dos anos 1990, a temática foi recolocada intensivamente no debate acadêmico segundo perspectiva que tenta romper com essa dualidade. A relação campo-cidade passa a ser abordada por diferentes perspectivas teóricas que privilegiam a leitura da realidade a partir dos processos que ocasionam transformações sociais na cidade e no campo. O debate é dado a partir de duas grandes abordagens norteadoras e problematizadoras: a abordagem clássica conhecida como dicotômica e a abordagem do continuum ruralurbano.

A primeira é caracterizada pelas oposições: rural-urbano, campo-cidade, tradicional-moderno. Os autores adeptos dessa corrente compreendem campo e cidade como espaços distintos, passíveis de serem analisados isoladamente, mas associados respectivamente a rural e a urbano. Esses autores sugerem em todas as oposições que o urbano prevalece sobre o rural, apontando a tendência de supressão do campo como efeito do processo de urbanização ${ }^{2}$.

Em contraposição, a vertente continuum rural-urbano supõe o fim do isolamento entre a cidade e o campo, tendo em vista que o espaço rural aproxima -se da realidade urbana em função do processo de urbanização. No entanto, dentro dessa vertente há divergências (WANDERLEY, 2001). Autores como Saraceno (1996) e Graziano da Silva (1997) consideram que devido ao processo de urbanização do

\footnotetext{
${ }^{2}$ Como exemplo, podem ser citados os trabalhos de Lefebvre (1974), realizado a partir da realidade europeia, e Queiroz (1973; 1976), Sorokin, Zimmerman e Galpin (1981) e Santos (2000), realizados no Brasil.
} 
campo, o rural tende a desaparecer; enquanto outros autores defendem que a globalização tem promovido a integração entre ambos os espaços, mas sem que o rural seja necessariamente extinto (MARQUES, 2002; WANDERLEY, 2001; CARNEIRO, 2002; VEIGA, 2000; 2003). No âmbito desse debate, para Wanderley (2001; 2009c) o espaço rural e o urbano são dois polos que se relacionam e, apesar das semelhanças que culminam na continuidade entre ambos, existem diferenças que os distinguem e caracterizam.

As reflexões de Wanderley $(2001 ; 2009$ c) sugerem a apreensão das diferenças espaciais e sociais sob uma ótica de análise que enfatiza a convergência entre o rural e o urbano na esfera local. O que significa dizer que no espaço local, independente de ser urbano ou rural, confluem aspectos desses dois polos. Nessa mesma perspectiva, Veiga (2003) afirma que as economias locais resultam de relações sinérgicas entre atividades urbanas e rurais.

De acordo com as reflexões trazidas por Veiga (2000; 2003), as interpretações sobre a realidade rural brasileira são inadequadas, tendo em vista que são construídas a partir da combinação pouco consistente de critérios relacionados às questões espaciais, localização, densidade demográfica e transformação do meio natural como convencionalmente vem sendo feito pelos órgãos oficiais e por alguns intelectuais. Em suas críticas, esse autor considera que a análise sobre o espaço rural é, na maioria das vezes, equivocada porque a tendência dos analistas é reduzir suas interpretações à associação entre o espaço rural (geográfico) e atividades agropecuárias, desconsiderando diversas outras características inerentes ao modo de vida da população rural. Apesar dessa visão, Marques (2002) avalia que Veiga faz uma análise instrumental por restringir-se à perspectiva econômica, negligenciando os aspectos sociais da relação campo-cidade. Outro ponto observado na abordagem feita nos trabalhos de Veiga é a valorização do fator densidade demográfica.

A despeito das críticas feitas por Marques (2002), Veiga traz contribuições importantes no debate contemporâneo sobre o rural, enfocando a necessidade de rompimento da ideia dual entre o rural e o urbano e o campo e a cidade a partir de uma abordagem territorial. Nessa mesma perspectiva, Abramovay (2009) enfoca que as transformações no rural devem ser tratadas a partir de uma abordagem territorial da ruralidade que, enquanto categoria analítica, aborda a relação com a natureza, a importância das áreas não povoadas densamente e a relação com as cidades. Em acordo com as reflexões de Veiga, o autor sugere uma definição territorial do meio rural (e do desenvolvimento), uma vez que:

Esta definição não é útil apenas para as áreas mais desenvolvidas do país, ela pode revelar dimensões inéditas das relações campo-cidade e, sobretudo, mostrar dinâmicas regionais em que as pequenas aglomerações urbanas dependem do seu entorno disperso para estabelecerem contato com a economia nacional e global, seja por meio da agricultura, seja por outras atividades (ABRAMOVAY, 2009, p. 33).

Apesar de considerar que as áreas com menor densidade demográfica têm significativa importância para as regiões rurais, Abramovay (2009) ressalta que estas regiões dependem direta ou indiretamente dos centros metropolitanos, o que torna fundamental a perspectiva territorial para compreender as relações entre campo e cidade. Simpatizantes desse ponto de vista, Wanderley (2009a; 2009c) e Medeiros (2011) concordam que as discussões contemporâneas sobre campo e cidade e rural e urbano são transversais à discussão sobre ruralidade. Medeiros (2011) define ruralidade como "um modo de vida, como uma sociabilidade que é pertinente ao mundo rural, com relações internas específicas e diversas do modo de viver urbano" (p. 61). Autores como Abramovay, Wanderley e Carneiro têm verificado transformações sociais no campo que apontam a emergência de novas ruralidades. 
É com essa perspectiva que os cientistas sociais nos últimos anos têm feito referências à relação campo-cidade para compreender os fenômenos que têm ocorrido no rural. No entanto, é preciso relativizar a tendência homogeneizante do "novo" rural brasileiro para não perder de vista as relações que conectam campo e cidade e que configuram diferentes ruralidades, principalmente porque os processos de mudanças no rural não ocorrem do mesmo modo em todo território brasileiro.

Nos estudos sobre o rural na região amazônica, por exemplo, a relação entre campo e cidade tem aparecido timidamente. Pesquisadores como Cardoso (2006) e Castro (2006) vêm refletindo sobre o rural e o urbano no contexto do processo de urbanização na Amazônia, apontando para a necessidade de repensar a construção e o uso do espaço rural-urbano. Dessa forma, a relação campo-cidade tem sido tratada de forma transversal em diversos trabalhos que seguem a direção apontada pelas autoras.

No prefácio da coletânea organizada por Cardoso (2006), a pesquisadora Edna Castro ressalta o desafio da não repetição da análise segmentada do urbano e do rural ao se estudar o contexto amazônico, tendo em vista que para a autora, esses espaços são partes inseparáveis da dinâmica territorial. Ao assumir esse posicionamento, Castro (2006) comunga da abordagem territorial enfatizada por Veiga (2003) e por Abramovay (2009). Longe de aprofundar o debate sobre a urbanização da Amazônia, nos itens a seguir serão discutidas as articulações entre campo e cidade por meio da mobilidade espacial dos agricultores, configurando um espaço territorial dinâmico onde rural e urbano são diluídos e ressignificados.

\section{PROCEDIMENTOS METODOLÓGICOS DA PESQUISA DE CAMPO}

O estudo foi realizado na área geográfica situada no entorno da vila Santa $\mathrm{Fé}^{3}$, distrito fundado na década de 1970 e situado a $72 \mathrm{~km}$ da sede municipal de Marabá. De acordo com dados do IBGE, esse município, distante a $485 \mathrm{~km}$ da capital Belém; tem área de $15.128 \mathrm{~km}^{2}$, população de 233.669 habitantes e está situado na região sudeste do estado do Pará (BRASIL, 2010).

A área do estudo foi colonizada paulatinamente por famílias agricultoras entre as décadas de 1960 e 1990. Atualmente é formada por projetos de assentamentos, áreas de colonização antiga, fazendas e pela sede distrital, cuja população é estimada pelos moradores locais em 6.000 habitantes.

Os dados empíricos foram obtidos através de pesquisa de campo feita nos meses de maio e agosto de 2010. As ferramentas utilizadas para coleta de dados foram entrevistas com famílias agricultoras e informantes-chave (moradores antigos e lideranças), observação direta e consulta a fontes secundárias, como os planos de desenvolvimento elaborados pelas prestadoras de serviço de assistência técnica aos projetos de assentamento. Além de cinco entrevistas feitas com informantes-chave para se obter informações sobre o histórico de ocupação da área de estudo, foram realizadas 28 entrevistas, sendo $26 \mathrm{com}$ agricultores familiares dos projetos de assentamento Tamboril, Dourada, Voltinha do Itacaiúnas, Bom Jardim e Murajuba e

\footnotetext{
${ }^{3} \mathrm{Na}$ definição feita pelo Instituto de Geografia e Estatística- IBGE a vila referida neste trabalho insere-se na descrição do aglomerado rural do tipo povoado que, de acordo com a classificação oficial, é caracterizado pela existência de serviços para atender aos moradores do próprio aglomerado ou de áreas rurais próximas, existindo um número mínimo de serviços ou equipamentos (BRASIL, 2000). Nesta definição as vilas, assim como as cidades, podem ter áreas urbanizadas ou não, e sua população é considerada urbana, independente destas estarem situadas no espaço geograficamente considerado rural.
} 
duas com agricultores da comunidade Jatobá I (área titulada por ser colonização antiga). Nessas entrevistas foram utilizados questionários semi-estruturados contendo questões relacionadas à história de vida das famílias (composição do grupo doméstico, origem, migração), atividades produtivas e formas de acesso aos serviços de saúde, educação e lazer.

\section{RESULTADOS E DISCUSSÃO}

\subsection{O Processo de ocupação do Sudeste paraense contextualizando a emergência das relações entre campo e cidade}

O surgimento de núcleos de povoamento no cenário brasileiro resulta da integração de uma série de variáveis como o processo de colonização, a estrutura fundiária e a necessidade de expansão do poder (MARX,1991; REIS, 2006 e SUZUKI, $2007)^{4}$.

No caso do sudeste paraense, a partir de revisão bibliográfica, é possível identificar três períodos marcantes na constituição e expansão de núcleos de povoamento nessa região:

1) período colonial até 1892: a região era habitada por índios e caboclos, com moradias e poucos povoados, situados às margens dos rios;

2) período de 1892 a 1960: época da extração da borracha, castanha e diamante, dando início à ocupação de áreas afastadas da margens dos rios por migrantes e implantação do sistema de barracões que originou novos núcleos e cidades; e

3) período pós década de 1960: colonização mais intensa ocasionada pela abertura de rodovias, descoberta do ouro em Serra Pelada, da madeira, implantação de grandes empreendimentos hidrelétricos, minerais e agropecuários, havendo a criação de novos núcleos e cidades e expansão das atividades agrícolas.

Durante o período do Brasil Colonial, os centros urbanos eram formados para dar suporte à agricultura de exportação, funcionando como centros comerciais de venda de produtos extrativistas e agrícolas e de recebimento de produtos manufaturados, criando uma relação entre o rural e o urbano pautada na comercialização de produtos e na oferta de serviços que permitiam o funcionamento do sistema comercial (REIS, 2006).

As missões jesuítas que inicialmente exploravam recursos naturais reconhecidos na historiografia como drogas do sertão ${ }^{5}$ e o ciclo da borracha contribuíram de forma estruturante para o povoamento da Amazônia brasileira. No período colonial, a ocupação dessa região era feita através das expedições que traziam escravos e da vinda de nordestinos retirantes por conta da seca no Nordeste. A malha hidrográfica da Amazônia, além de facilitar o fluxo migratório e o transporte de mercadorias, também formava uma rede de povoados a partir dos quais se desenvolviam relações estruturantes da vida das pessoas. A rede de povoados e a estrutura social formada a partir dela foram fundamentais para a expansão do domínio português na região Norte do Brasil.

\footnotetext{
${ }^{4}$ No geral, as aglomerações urbanas foram espaços fundamentais na difusão do poder da coroa portuguesa, tendo em vista que nas vilas e nas cidades, estava situada a representação legal do poder da coroa e da lgreja (MARX, 1991; SUZUKI, 2007).

${ }^{5}$ Especiarias encontradas nas matas brasileiras e de grande valor no mercado europeu nos séculos XV, XVI e XII.
} 
A partir de meados do século $\mathrm{XIX}$ até início do século $\mathrm{XX}$, a exploração da borracha definiu o surgimento e expansão de novas aglomerações humanas que tinham na cadeia de comercialização do látex seus elementos estruturantes. Manaus, no Amazonas e Belém, no Pará, passaram a serem as metrópoles da Amazônia, atraindo os aspectos relacionados às cidades "civilizadas", como a arquitetura moderna na época, construção de teatro e hotéis, expansão do comércio, dentre outros, simbolizando os avanços da urbanização da região Norte do país.

Com o declínio da fase áurea de exploração desse produto nas primeiras duas décadas do século $X X$, outras frentes de migração sustentaram os núcleos de povoamento existentes e estimularam o surgimento e expansão de outros, principalmente a extração de castanha (Bertholletia excelsa) e a abertura da fronteira agrícola amazônica. Segundo Hébette $(1989 ; 2004)$ a partir da década de 1960, as ações do Estado foram motoras do fluxo migratório para a região amazônica e, consequentemente, para a expansão da rede urbana, tais como: construção dos grandes eixos viários; criação da Superintendência de Desenvolvimento da Amazônia (SUDAM); implantação de grandes projetos a exemplo da construção de hidrelétricas em Rondônia, Goiás (atualmente estado do Tocantins) e Pará, do projeto Jarí e de outros vinculados ao Programa Grande Carajás (PGC). É nesse contexto de estímulo governamental à ocupação da Amazônia durante as décadas de 1960 e 1970 que a região sudeste paraense passou a ser intensamente ocupada por investidores privados e por migrantes à procura de terra e de emprego ${ }^{6}$.

$\mathrm{Na}$ década de 1980, a exploração madeireira, facilitada pela melhoria das estradas, também contribuiu como elemento de atração. Nessa mesma década, a mineração passou a ser a atividade atrativa de uma nova frente de migração, sem, no entanto, reduzir a característica agropecuária da fronteira, haja vista que a exploração dos recursos hídricos e minerais ocorreu concomitante à expansão da fronteira agrícola que passava a ser preenchida por famílias agricultoras oriundas das diversas regiões brasileiras (HÉBETTE, 2004).

Em vista de eventos como a construção da Usina Hidrelétrica (UHE) de Tucuruí, a conclusão das obras de implantação da Companhia Vale do Rio Doce (CVRD), em Carajás, o encerramento da atividade de garimpo em Serra Pelada e garimpos vizinhos, uma parcela significativa da população permaneceu na região das minas, enquanto outra parcela migrou para os centros urbanos próximos (principalmente para a cidade de Marabá) e para outros locais onde pudessem adquirir terra ou conseguir emprego (EMMI, 1989; HÉBETTE, 1989).

Dessa forma, os investimentos federais resultaram não apenas na formação de novos núcleos, mas também na reconfiguração espacial do povoamento da Amazônia que passa a se caracterizar não mais pela predominância de cidades, vilas e povoados ribeirinhos, mas também por aglomerações à margem de estradas e ferrovias que passam a atrair e concentrar novos migrantes. Em alguns desses lugares, povoados, vilas e cidades foram planejados dentro dos projetos de colonização oficial, chamados de Projetos Integrados de Colonização (PIC), para serem formados e/ou expandidos ao longo das rodovias como locais de oferta a bens e serviços para os migrantes, como as cidades de Brasil Novo, Medicilândia, Uruará e Rurópolis, ambas situadas no sudoeste paraense.

\footnotetext{
6 Um dos focos do Governo Federal da época era a expansão da fronteira agrícola e para tal "componente fundamental dessa abertura foi a implantação dos grandes eixos rodoviários para estimular a mobilidade e a circulação de pessoas e mercadorias (HÉBETTE, 1989, p. 10).
} 


\subsection{Conectando campo e cidade: reflexões a partir da situação a região da Santa Fé}

O processo de ocupação da região sudeste paraense está associado a um conjunto de eventos regionais, tais como a migração originada pelo extrativismo da castanha, abertura de estradas, instalação de madeireiras, mineração e recentemente criação de projetos de assentamentos (HÉBETTE, 2004). Na medida em que tais eventos aconteceram, e a fronteira agrícola fora se expandindo, vilas e cidades emergiram, formando um universo dinâmico aonde campo e cidade foram constituídos em constante interação.

Os núcleos de povoamento, principalmente a cidade de Marabá, polo regional em termos de infraestrutura e serviços, têm contribuído significativamente para a melhoria das condições de vida das famílias agricultoras por facilitar o acesso a bens e serviços que estas demandam, tal como observado a partir da pesquisa empírica no entorno da vila Santa Fé. Essa área geográfica do interior do município começou a ser ocupada em período anterior à década de 1970 a partir da malha hidrográfica que favoreceu a chegada dos migrantes e o escoamento dos produtos extrativistas (castanha, madeira e pele de animais). No final da década de 1970 houve a fundação da vila que passou a ser o entreposto comercial.

A ocupação no entorno do núcleo de povoamento foi intensificada durante a década de 1980 quando houve abertura de estradas e exploração madeireira, conforme ocorrera na terceira fase de ocupação do sudeste paraense. Além das atividades extrativistas, as famílias investiram na atividade agrícola, em especial no cultivo de lavoura branca ${ }^{9}$. Na década de 1990, novas áreas foram ocupadas e regularizadas como projeto de assentamento, aumentando a população regional e a produção agrícola. Devido ao grande número de crédito agrícola liberado, em meados dessa década, a atividade pecuária bovina passou a movimentar a economia regional conjuntamente com o cultivo de cereais, produção de farinha e atividade madeireira.

Apesar de essa área geográfica estar situada a mais de $70 \mathrm{~km}$ da sede municipal, os dados mostram que desde a chegada ao lote agrícola, as famílias estabeleceram vínculos com a cidade de Marabá, uma vez que esta era o centro de serviços mais próximo. Nas décadas de 1970 e 1980, época de estrada intrafegável e da inexistência de linha de transporte regular nos sentidos vila-cidade e cidade-vila, os agricultores deslocavam-se com muita dificuldade para Marabá a fim de fazer compras para suprir as necessidades familiares, buscar atendimento médico, vender produtos agrícolas, resolver questões relacionadas a serviços bancários e documentações (pessoais e/ou em relação à terra), para adquirir insumos e ferramentas e visitar parentes. Nesse período, a vila Santa Fé era formada por poucas casas e alguns pequenos estabelecimentos comerciais.

A frequência de ida à cidade dependia (e depende) de alguns aspectos, como a disponibilidade de transporte, período do ciclo agrícola, condição financeira e a urgência do motivo. No geral, era (e ainda é) de responsabilidade masculina ir a Marabá para resolver esses assuntos, enquanto as mulheres geralmente deslocam-se para lá na intenção de visitar parentes e ir ao médico. No caso dos jovens, a ida para a cidade normalmente era definitiva ao invés de esporádica, pois era para lá que se dirigiam para ter acesso à escola.

\footnotetext{
9 Lavoura branca é o termo utilizado para designar os cultivos anuais, especificamente lavoura de arroz, milho, feijão e mandioca.
} 
Nas décadas de 1980 e 1990 aumentou significativamente a população da região do sudeste paraense devido a fatores associados à migração interestadual, ao aumento da taxa de natalidade e à migração interna promovida não somente por migrantes, mas por seus filhos que formam uma segunda geração de migração intrarregional.

A partir de meados da década de 1980 as ações governamentais de regularização fundiária contribuíram para a conformação socioespacial regional. Nas duas últimas décadas, o investimento na criação de assentamentos rurais influenciou diretamente tal conformação ${ }^{7}$. Até 2008, nessa região haviam sido criados 481 assentamentos de reforma agrária, significando, segundo dados do Instituto Nacional de Colonização e Reforma Agrária (INCRA), a ocupação de 34 por cento do total da área geográfica do sudeste paraense (ASSIS; OLIVEIRA; HALMENSCHLAGER, 2009).

Ao longo do processo de ocupação recente do sudeste paraense, os estudos de Velho (1979), Castro e Hébette (1989) e Hébette (2004) demonstram que a formação dos núcleos de povoamento tem aspectos semelhantes aos que se observara no período colonial no que concerne a construção de espaços de socialização ${ }^{8}$. Além das aglomerações serem vistas como centro estratégico para a comercialização dos produtos agrícolas e para a instalação da administração municipal (e do poder público), lá eram construídas igrejas e campos de futebol. Logo, a centralização de bens e serviços exprime a função dos núcleos de povoamento na organização do espaço e nas formas de acesso a serviços públicos e privados, assim como apontado por Wanderley (2001; 2009c). Velho (1979) e Hébette (2004) explicam que dentre os aglomerados emergentes ao longo do processo de ocupação do sudeste paraense, a cidade de Marabá tornou-se o principal centro urbano regional devido à condição de entreposto comercial que assumira desde o início de sua formação final do século XIX. Devido à sua privilegiada localização geográfica que viabilizava as relações comerciais por permitir o escoamento dos produtos agrícolas e a importação dos bens manufaturados, esse núcleo de povoamento passou a ser o local central de oferta das condições mínimas de infraestrutura, tais como comércio, escolas e hospital. $\mathrm{Na}$ atualidade, Assis, Halmenschlager e Oliveira (2009) destacam o município de Marabá como "o mais importante centro financeiro, comercial, da construção civil, de oferta de empregos e de serviços de saúde, educação e outros serviços públicos [...]" (ASSIS; HALMENSCHLAGER; OLIVEIRA, 2009, p. 178). No entanto, ressalta-se que, à medida que as áreas ocupadas pelos agricultores distanciavam-se das sedes municipais, novos núcleos de povoamento emergiam, configurando vilas e povoados dispersos na área geográfica dos municípios, complexificando a dinâmica territorial regional.

\footnotetext{
7 A criação de assentamentos é um dos fatores responsável, dentre outros aspectos, pela distribuição de recursos públicos através de diversas políticas e programas de governo, pelo surgimento de novos arranjos produtivos e pelo estabelecimento de novas formas de sociabilidade, interferindo diretamente na distribuição demográfica e na paisagem natural. De acordo com os estudos feitos por Magalhães (2003) e Michelotti et al. (2007), na região de Marabá a criação de assentamentos rurais é caracterizada pela regularização fundiária conquistada através da pressão das organizações sociais rurais, principalmente no final da década de 1980 e 1990.

${ }^{8}$ Todavia, nesse período a relação de poder entre a lgreja e o Estado já não é estreita, o comércio tem outras funções e os espaços de lazer podem ser diferentes.
} 
$\mathrm{Na}$ década de 1990 algumas mudanças estruturais na vila e no seu entorno contribuíram para a transformação da sociedade local, tais como: a) o comércio de produtos agrícolas e de bens manufaturados foi incrementado com a presença de novos comerciantes, muitos deles também agricultores; b) as estratégias produtivas dos agricultores definiram novas relações comerciais; e c) o Estado aumentou os investimentos melhorando a infraestrutura local na área da saúde, educação e vias de comunicação. Como efeito de tais fatores, as relações estabelecidas com a cidade de Marabá foram redesenhadas, mas sem perder de vista suas dimensões econômicas, político-administrativas e de sociabilidade.

\subsubsection{Conexões entre agricultores e a cidade}

Os vínculos que conectam os agricultores à cidade formam um tecido de laços que corroboram para a construção da dinâmica social municipal, o que torna desafiador fragmentar e tratá-los de forma isolada. No entanto, no exercício de ressaltar a diversidade de fatores que integram campo e cidade, faremos a seguir o esforço de demonstrar os tipos de relações que os agricultores têm estabelecidos devido aos vínculos com a cidade de Marabá.

a) Relações econômicas

A inserção nos circuitos mercantis é um dos fatores geradores da mobilidade espacial que integra os agricultores com a sociedade "englobante", o que atribui às relações econômicas condição importante da quebra do isolamento daqueles que vivem afastados dos núcleos de povoamento (QUEIROZ, 1973; 1976, WANDERLEY, 2009c). Na situação estudada, observou-se que ao longo das décadas, as relações econômicas tiveram significativa importância para integrar campo e cidade através da venda e compra de produtos. Numa perspectiva temporal, as relações econômicas evoluíram da seguinte maneira:

- Década de 1970: a venda de produtos extrativistas e agrícolas, principalmente arroz, era feita para atravessadores que buscavam a produção no lote. A negociação era feita ou na região da Santa Fé, quando o comprador saía à procura de produtos, ou na cidade de Marabá quando os agricultores deslocavam-se para lá, no intuito de oferecer a produção colhida/extraída. Os produtos manufaturados eram comprados por intermédio dos atravessadores ou por ocasião da ida à cidade;

- Década de 1980: comerciantes (donos de usina de arroz e de armazéns cerealistas) instalaram-se na vila, e a venda de produtos extrativistas e agrícolas passou a ser negociada lá. Os produtos manufaturados continuaram a ser comprados através dos atravessadores ou por ocasião de ida à cidade;

- Década de 1990: houve a redução da produção de lavoura branca e aumento na criação de gado, cujos produtos vendidos eram negociados na vila ou no projeto de assentamento. Porém, a melhoria das estradas de acesso à cidade e funcionamento do sistema de transporte ${ }^{10}$, permitiu que os agricultores levassem alguns produtos para vender na cidade quando fossem para lá (independente do motivo). Geralmente

10 O sistema de transporte corresponde aos carros privados que fazem linha para a cidade diariamente. Regionalmente os veículos de transporte coletivo utilizados para locomoção nos trajetos vila-cidade-vila ou projeto de assentamento-cidade-projeto de cidade são chamados de carros de linha. 
eram galinhas, ovos e queijo que eram vendidos de "porta-em-porta". O rancho ${ }^{11}$ e produtos manufaturados começaram a ser comprados nos comércios da vila, mas são adquiridos principalmente na cidade, incluindo gêneros alimentícios e artefatos pessoais ${ }^{12}$

- A partir do ano 2000: a situação assemelha-se com a da década anterior. Geralmente o rancho é feito regularmente nos comércios de Marabá quando os agricultores vão receber aposentadoria ou salários (no caso daqueles que são funcionários públicos) ou, quando para lá se deslocam por alguma outra eventualidade. Mas há momentos em que os gêneros alimentícios são comprados nos comércios da vila. Artigos de vestuários e artefatos pessoais são comprados na cidade. Os agricultores deixaram de vender queijo na cidade devido à fiscalização dos agentes da vigilância sanitária nos carros de linha, mas alguns continuam a vender aves esporadicamente.

Essa situação difere em se tratando das famílias situadas na beira da estrada do Rio Preto, entre a vila e a cidade, e nas comunidades onde há meio de transporte direto para a cidade, como é o caso do Projeto de Assentamento (PA) Murajuba. Essas famílias mantêm relações comerciais direto com consumidores em Marabá através da venda de produtos agrícolas e extrativistas, como arroz, feijão, milho e castanha. As famílias dessa região se articulam para vender os produtos diretos aos cerealistas, sem intermédio de terceiros ou na feira.

Algumas famílias mudaram ao longo do tempo suas estratégias produtivas, e as mudanças influenciaram a forma como elas se relacionam com os agentes de comercialização e os consumidores. Famílias que antes vendiam seus produtos em Marabá hoje estão inseridas no circuito comercial local. Outras, no entanto, estreitaram os laços comerciais com consumidores da cidade, como no caso das famílias que participam da feira. Para essas famílias, manter relação econômica com a cidade faz parte de suas estratégias de inserção no mercado, expandido suas relações econômicas para além da região da Santa Fé.

A diversificação do comércio na vila foi um dos fatores que mais tem contribuído no processo de mudança das relações econômicas que os agricultores mantinham com a cidade, uma vez que "[...] é o lugar mais próximo. Na precisão aí tem (remédio, coisa de comer)", diz o Sr Durvalino ${ }^{13}$. Ao falar que "na precisão aí tem", o agricultor referese ao fato de que hoje na vila são encontrados suprimentos básicos das necessidades das famílias, o que antes só era possível em Marabá, a uma distância de 70 quilômetros. Por isso, a vila assume importante papel na provisão de mercadorias para os moradores do seu entorno.

Todavia, isso não significa a desvinculação com o comércio de Marabá. Para muitas famílias, as compras na vila são feitas em "caso de precisão" porque, como diz D. Hilda, "coisa para os meninos, roupa, feira grande é tudo em Marabá" (HILDA, agricultora e professora, agosto de 2010). Dessa forma, os vínculos mercantis mantidos com a cidade são constituídos a partir da aquisição de bens manufaturados

\footnotetext{
${ }^{11} \mathrm{O}$ rancho assemelha-se à cesta básica: é o conjunto de alimentos não produzidos no lote, mas que são considerados importantes na alimentação básica, como café, óleo, açúcar, macarrão e outros industrializados. Fazer o rancho significa efetuar a compra do conjunto de alimentos como esses.

${ }^{12} \mathrm{O}$ fato dos moradores comprarem na vila apenas mercadorias em pouca quantidade enquanto não vão à cidade, justifica-se por duas questões: uma relacionada aos preços dos produtos que na vila é bem superior se comparado aos supermercados e lojas de Marabá; e outra relacionada à ida frequente para a cidade.

${ }^{13}$ Para preservar a identidade dos entrevistados, os nomes citados neste trabalho são fictícios e inspirados no livro Tocaia Grande: a face obscura, do romancista brasileiro Jorge Amado, não havendo qualquer semelhança entre personagens e entrevistados.
} 
e produtos não produzidos no lote e das diversas formas de comercialização dos produtos. Enquanto a aquisição de bens e produtos depende das condições financeiras das famílias e das condições de transporte, as formas de comercialização estão conectadas às estratégias produtivas das famílias. Os tipos de produtos comercializados dependem de fatores relacionados à disponibilidade de recursos naturais e mão de obra familiar para implantação de cultivos, meio de transporte para escoamento da produção e à possibilidade de inserção em mercados.

Dessa forma, mesmo a vila influenciando diretamente nas atividades cotidianas das famílias agricultoras das áreas circunvizinhas, não se pode desconsiderar as funções que também tem a cidade de Marabá, uma vez que Marabá "é o centro comercial maior. Tudo que você procura, a gente acha. Médico, banco, comprar roupa, calçado, é tudo em Marabá, banco..." (ABGAIL, agricultora, agosto de 2010).

b) Relações político-administrativas

A busca pelos serviços públicos considerados básicos no exercício da cidadania é um dos elementos que integra os agricultores à cidade. O fato de a cidade concentrar os serviços públicos de educação, escola, sedes administrativas de órgãos públicos, privados e das organizações sociais, cartórios, banco e comércio, faz com que a circulação espacial dos agricultores seja recorrente e reforça o papel das cidades enquanto centro de serviços.

Durante as décadas de 1970 e 1980 a ida dos agricultores à Marabá era pontual no caso daqueles que precisam recorrer a serviços esporádicos, como atendimento médico e serviços burocráticos. Por outro lado, era regular para aqueles que desejavam frequentar a escola, como na situação dos filhos dos agricultores ${ }^{14}$. Em muitos casos, a mudança para cidade perdeu o caráter de temporada ou de transição e transformou-se em definitiva à medida que os filhos começavam a se integrar ao cotidiano dos centros urbanos de forma mais efetiva, seja através de postos de trabalho ou de casamento.

A partir da década de 1990, as ações estatais associadas à política de reforma agrária exigiram dos agricultores maior frequência de ida à cidade, uma vez que é lá onde são resolvidos os aspectos burocráticos relacionados ao assentamento no lote e ao acesso aos créditos habitação e agrícola. $O$ acesso aos recursos das políticas de transferência de renda, como aposentadoria e bolsa família, também condiciona os agricultores beneficiados a frequentarem a cidade para acessar o sistema bancário. Outros fatores relacionados às atividades agropecuárias, como cadastramento da vacinação do rebanho bovino e retirada da Guia de Trânsito Animal (GTA) para a venda do gado, também corroboram com a dimensão político-administrativa das relações estabelecidas com Marabá.

Ainda a partir dos anos de 1990 houve a reconfiguração de algumas dessas relações, mas em sentido contrário. Não foi somente a expansão do comércio local na vila que influiu nas modificações dos laços com Marabá. As mudanças estruturais condicionaram as modificações de algumas relações político-administrativas que os agricultores estabeleciam por ocasião da centralização dos serviços públicos na cidade de Marabá, principalmente no que diz respeito ao estudo dos filhos. A existência de escolas na vila alterou a forma de acesso dos filhos e netos dos

\footnotetext{
14 Até meados da década de 1990, a precariedade ou inexistência de escolas de ensino fundamental e médio no assentamento e na vila fez com que os agricultores investissem na saída dos filhos para estudar na cidade de Marabá.
} 
principalmente quando há programações vistas como "especiais", tais como festividades religiosas, shows e aniversários. Ou ainda para sair com os amigos e parentes, frequentar ambientes e realizar atividades lúdicas que não são possíveis de serem realizadas na vila e no seu entorno.

Para os agricultores, essas características associadas às anteriormente descritas marcam as diferenças entre campo e cidade e entre rural e urbano, traçando uma linha associativa entre o rural visto como atrasado e o urbano visto como moderno, tal como pode ser observado em trabalhos afiliados à literatura clássica sobre a relação campo-cidade, como em Lefebvre (1974) e Queiroz (1973; 1976).

\subsection{Campo e cidade: conectividade e conformação da dinâmica regional}

De acordo com as reflexões de Wanderley (2009b; 2009c) e Veiga (2000; 2003), na cidade acontece o exercício das funções propriamente urbanas relacionadas à centralização das atividades econômicas e sócio-políticas do conjunto do espaço local, envolvendo a concentração das atividades administrativas municipais, a oferta de serviços e centralização do poder, enquanto as atividades rurais estão relacionadas à exploração dos recursos naturais.

Atualmente, o acesso a serviços médicos, serviços bancários e em órgãos públicos é o que mais tem contribuído para conectar os agricultores à cidade. No entanto, a criação de escolas e a ampliação do sistema comercial na vila Santa Fé têm reconfigurado essa conexão, mas sem diminuir a importância de Marabá enquanto centro de serviços. Devido a esses aspectos, a realidade encontrada na região da Santa Fé vai ao encontro das reflexões de Wanderley quando diz que:

No caso do meio rural , o que precisamente se define como uma aglomeração poucos são os serviços, bem como as ofertas de trabalho, dissponíveis no próprio lugar de residência. A consequência é a impossibilidade de acesso, o que gera a precariedade registrada em grande parte das áreas rurais brasileiras, ou a necessidade de deslocamento da população local numa área de circulação que frequentemente ultrapassa os limites deslocamento da população local numa área de circulação que frequentemente ultrapassa os limites do próprio mundo rural e às quais a população do campo, não raro, chega fragilizada (WANDE, 2009, p.18).

Apesar das transformações em algumas relações, a cidade de Marabá constitui-se enquanto espaço relevante para as famílias agricultoras pelos motivos apontados anteriormente, o que a torna complementar ao rural. Devido o papel que a cidade exerce na construção do cotidiano dos agricultores, Wolf (1976) diz que:

[...] gostaria de pensar na cidade como um local habitado no qual se exerce uma combinação de funções, tornando-se útil, porque com o tempo se consegue uma eficiência maior através da centralização dessas funções em um ponto determinado (WOLF, 1976, p. 25).

Apesar de a cidade ser um espaço que centraliza algumas funções, sua utilidade e eficiência tornam-se questionáveis quando a centralização de determinadas funções passa a dificultar o acesso às mesmas. Ao se considerar o acesso a serviços das pessoas que moram afastadas da sede municipal e a estrutura organizacional de 
agricultores ao estudo porque, de acordo com o Sr Cristóvão, "às vezes para colocar os meninos em Marabá é difícil e tendo aí (na vila), estuda na Santa Fé".

Em relação ao serviço público de saúde, as situações consideradas mais simples são resolvidas no posto de saúde, já nos casos mais graves que necessitem de atendimento de pronto-socorro ou de realizar exames e consultas médicas, os agricultores procuram o Hospital Municipal de Marabá. Isso implica em deslocamento para a sede municipal e agendamento prévio das consultas e exames. As famílias que dispõem de melhor condição econômica recorrem ao atendimento médico em outras cidades onde consideram que o serviço médico privado seja mais qualificado, rápido e acessível em termos financeiros ${ }^{15}$.

Além do acesso aos serviços públicos, a participação política dos agricultores está vinculada à sede municipal, uma vez que na cidade estão as sedes administrativas dos órgãos estatais e do Sindicato de Trabalhadores Rurais (STR), principal entidade representativa dos agricultores familiares. Dessa forma, os agricultores deslocam-se para a cidade de Marabá também pelos seguintes motivos: resolução de questões burocráticas referentes ao funcionamento das entidades representativas (associações e sindicato), manifestações públicas, reunião com representantes públicos e reuniões do sindicato, principalmente no caso daqueles que ocupam cargo na diretoria do sindicato e/ou das associações.

c) Relações de parentesco e amizade

Não somente as relações mercantis e político-administrativas contribuíram para a circulação dos agricultores dentro do município. As relações de parentesco e de amizade também subscrevem idas e vindas dos agricultores em direção à cidade para visitar parentes e amigos que lá residem e vice-versa. Esses laços pessoais são exemplos da integração social que conformam a cidade como espaço de sociabilidade. A cidade assume importância diferenciada para aquelas famílias cujos membros lá estabeleceram residência. Geralmente são os filhos que saíram do lote em busca de estudo ou de emprego, ou parentes que não conseguiram terra e que optaram pela vida "urbana". Para o Sr. Pedro Cigano, por exemplo, a cidade é importante porque lá seus filhos estão "bem empregados". Já para $\mathrm{D}$. Abgail, além de ser importante por ser a cidade onde seus filhos estudam, é o lugar onde sua mãe, já idosa, reside "com mais conforto".

Logo, a cidade é vista como local de oportunidade de trabalho menos sofrido que o trabalho no campo e de vida mais confortável. O trabalho é visto como menos sofrido quando congrega principalmente oito horas de trabalho diário (ou menos) e salário fixo, enquanto o conforto refere-se à proximidade aos locais de serviços rotineiros e necessários, como serviços médicos e bancários e à infraestrutura, tal como: casa com energia elétrica, ruas iluminadas e asfaltadas, igrejas próximas, meio de transporte e espaços diversificados de lazer.

\section{d) Atividades de lazer}

Além de se constituir enquanto espaço de relações econômicas, políticoadministrativas e de visitas a parentes e amigos, a cidade de Marabá também é vista como local de diversão devido à diversidade de opções de estabelecimentos comerciais (bares, danceterias, restaurantes, lanchonetes, dentre outros), de praças, praias, festas, programações religiosas e outros eventos e ambientes de lazer. Comumente os agricultores programam ficar na cidade durante o final de semana,

\footnotetext{
${ }^{15}$ É o caso das cidades de Teresina-PI, Araguaína- TO e Goiânia- GO.
} 
Marabá, fatores como distância e demanda, comprometem a eficiência da centralização de recursos na cidade. Por isso é preciso considerar a descentralização dos serviços da sede municipal para disponibilizá-los nas vilas como uma possível estratégia para ampliar a possibilidade de acesso dos moradores da região da Santa Fé aos mesmos, tal como vem sendo feito no caso da implementação das escolas e do posto de saúde. Vale lembrar que a conquista dessas demandas não é gratuita, mas fruto de uma combinação de fatores que envolvem a organização social local e o poder de barganha dos atores envolvidos. Para conquistar os bens coletivos e as mudanças pretendidas em termos de infraestrutura na vila, os agricultores através de suas organizações têm utilizado estratégias para mobilizar os moradores locais para ações coletivas, como construção de cartas reivindicatórias e reuniões com representantes do poder público.

Por meio dessas mobilizações, os moradores da região têm pleiteadas e obtidas algumas conquistas junto ao poder público, como: a construção das escolas e do posto de saúde, a implantação do posto policial, da energia primeiramente a diesel e depois elétrica; a implantação de telefones públicos e também de linha privada, do posto de correio e de uma sede sindical (STR). Mais recentemente têm sido incluídos na pauta apresentada pela associação dos moradores da vila e região à prefeitura de Marabá, o término da construção da praça, o atendimento médico odontológico semanal, o asfaltamento das ruas, a implantação do sistema de distribuição de água e do serviço de telefonia celular e o licenciamento de uma linha de táxi da vila para a cidade de Marabá.

O estabelecimento de parcerias entre as representações dos agricultores familiares, instituições governamentais, como as prefeituras municipais, e outras entidades, pode fortalecer a ação conjunta entre estes para conseguir implementar as ações necessárias para garantir o acesso dos agricultores aos recursos de políticas públicas.

Lembrando os trabalhos de Wanderley $(2001 ; 2009 b ; 2009 c)$ e Soares (2011), observa-se que de forma associada, as estruturas físicas para o fornecimento de serviços e para a realização dos mais diversos tipos de atividades confluem para o hibridismo entre os aspectos da vida rural e da vida citadina, viabilizando condições necessárias para o fortalecimento da agricultura familiar e dinamizand o a sociedade do qual os agricultores fazem parte. No entanto, diferente do que apontam Carneiro (1998; 2002), Abramovay (2009) e Marafon (2011), as mudanças na relação campocidade no contexto estudado não derivam da emergência de novas ruralidades, como observado em municípios da região sudeste. Esses autores consideram que a análise da relação entre campo e cidade na atualidade do contexto brasileiro aponta para novas ruralidades que são decorrentes da emergência de novas atividades no campo e são caracterizadas por fatores como emprego significativo da mão de obra familiar em atividades não agrícolas, campo como local de morada, lazer, turismo e natureza e cidade como local de trabalho.

Na situação analisada, o campo continua sendo local de morada e trabalho dos agricultores familiares, predominando a atividade agrícola. Apesar dos atrativos da cidade, a infraestrutura existente na vila aproxima os moradores locais dos serviços citadinos, contribuindo para a manutenção e fortalecimento das formas de sociabilidade e da integração entre os espaços, sem significar a "urbanização" do rural. Como demonstrado por Wolf (1976) e por Wanderley (2009b), os núcleos de povoamento são estruturantes e inerentes à conformação dos modos de vida dos agricultores. Esses núcleos não apenas surgem do rural, como também estão no cerne de sua formação. 


\section{CONSIDERAÇÕES FINAIS}

De modo geral, desde o período colonial, os núcleos de povoamento, tanto cidade quanto vila, desempenham papel importante na configuração do espaço amazônico e na viabilização dos modos de vida das populações que compunham tal cenário. No município de Marabá, as transformações sociais recentes evidenciadas no caso estudado apontam que o espaço geográfico do município tem sido transformado ao longo do tempo tanto em termos de estrutura fundiária e produtiva, como também em termos de dinâmicas da sociedade local em função de diversos eventos suprarregionais. Nesse contexto, a conexão entre o campo e a cidade ocorre através do intercâmbio de elementos provedores da vida das famílias nesses dois espaços que se diluem através do continuum rural-urbano. Por isso, a discussão aqui apresentada aponta alguns pontos que são importantes na conformação da agricultura familiar e dos núcleos de povoamento, bem como na integração entre ambos, tais como: as atividades agropecuárias desenvolvidas; os serviços "urbanos" existentes; a atuação político-organizativa dos agricultores e as dinâmicas econômicas, sociais locais e globais que refletem e influenciam as mudanças sociais.

Observa-se que na situação estudada, o campo continua sendo espaço de produção agrícola habitado predominantemente por pessoas com trajetória familiar ligada ao trabalho na terra, apesar da conjuntura socioeconômica das famílias ser diferente da que se tinha até meados da década de 1990. Muitos aspectos relacionados ao meio biofísico, à organização sociopolítica, formas de acesso ao mercado e aos recursos públicos foram transformados ao longo do tempo em função das diferentes estratégias produtivas utilizadas pelos agricultores, de eventos regionais e nacionais, como a abertura da estrada e o investimento governamental em políticas e programas de governo, como crédito agrícola, ativação de escolas e do posto de saúde. Esses eventos resultam na interação entre múltiplos atores e entre múltiplos espaços.

Apesar de haver mudanças na relação campo-cidade, no contexto estudado não se observa a predominância de características que designam as "novas" ruralidades apontadas nos estudos de Carneiro, Abramovay e Marafon. As relações que os agricultores estabelecem com a cidade não expressam a emergência de novas funções para o campo e para a cidade, como apontam os estudos desses autores. $\mathrm{Na}$ situação analisada, o fato de o campo ser local de moradia e trabalho onde as atividades agrícolas também são definidoras do modo de vida local, não significa que esse espaço seja local descolado, isolado, estático e desprovido de características tratadas como urbanas, tais como serviços públicos, urbanização e setor de serviços. Ao contrário, apesar de suas particularidades em termos de organização socioespacial e econômica, está interconectado à cidade de Marabá devido às relações estabelecidas entre os moradores de ambos os locais pelos mais diversos motivos, sem que isso signifique a urbanização do campo.

A descentralização dos serviços tem redefinido os papéis desempenhados pela cidade pela vila no cotidiano dos agricultores, porém, ambos os espaços têm sido fundamentais para a melhoria das condições de vida da população local, uma vez que serviços vistos como urbanos são também pleiteados pelos que não residem na cidade. A tendência é que cada vez mais haja descentralização do setor de serviço e de serviços públicos, dependendo do poder de barganha da população local para pleitear e conquistá-los. Como a fronteira agrícola dessa parte da Amazônia está 
sendo movimentada por processos que configuram a estruturação dos núcleos de povoamento, sejam as vilas ou as cidades, supõe-se que a dinâmica social local sofra alterações, assim como a relação campo-cidade.

\section{REFERÊNCIAS BIBLIOGRÁFICAS}

ABRAMOVAY, R. O Futuro das Regiões Rurais. Porto Alegre: Ed.UFRGS. 2009. $2^{\mathrm{a} e d .}$ ASSIS, W. S. de; HALMENSCHLAGER, F. L; OLIVEIRA, M. Dinâmicas territoriais, projetos coletivos e as complexidades das áreas de fronteira agrária: o caso da região de Marabá, Pará.. In:CAZELLA, Ademir A; BONNAL, P.; MALUF, R. S. (orgs.).

Agricultura familiar: multifuncionalidade e desenvolvimento territorial no Brasil. $1^{\text {a }}$ ed. Rio de Janeiro: MAUAD. 2009, p. 167-192.

BRASIL. IBGE - INSTITUTO BRASILEIRO DE GEOGRAFIA E ESTATÍSTICA. 2000. Sinopse preliminar do censo demográfico. Rio de Janeiro, v.7. 2010. Sinopse preliminar do censo demográfico 2010. Rio de Janeiro.

Disponível em < http://www.ibge.gov.br/cidadesat/topwindow.htm?1> Acesso em: 10 maio 2013.

CARDOSO, A. C. D. (org). O Rural e o Urbano na Amazônia: diferentes olhares em perspectiva. Belém: EDUFPA. 2006.

CARNEIRO, M. J. Ruralidade: Novas identidades em construção. Estudos Sociedade e Agricultura, n. 11, outubro, 1998, p. 53-75. Rio de Janeiro: CPDA/UFRRJ Disponível em <http://r1.ufrrj.br/esa/art/199810-053-075.pdf>. Acesso em janeiro, 2010.

Multifuncionalidade da Agricultura e Ruralidade: uma abordagem comparativa. In: MOREIRA, J.; COSTA, L. F. C. (Org). Mundo Rural e Cultura. Coletânea Desenvolvimento, Agricultura, Sociedade e História Social, PRONEX. Rio de Janeiro: Ed. Mauad, 2002.

CASTRO, E. M. R. de; HÉBETTE, J. (orgs.) Na trilha dos grandes projetos: Modernização e conflitos na Amazônia. Belém: UFPA/NAEA. Cadernos NAEA, nº 10. 1989.

CASTRO, E. M. R. de. Prefácio. In: CARDOSO, Ana Claúdia Duarte (org). O Rural e o Urbano na Amazônia: diferentes olhares em perspectiva. Belém: EDUFPA. 2006.

EMMI, M. F. A oligarquia da Castanha: crise e rearticulação. In: CASTRO, Edna Maria Ramos de; HÉBETTE, J. (orgs.) Na trilha dos grandes projetos: Modernização e conflitos na Amazônia. Belém: UFPA/NAEA. Cadernos NAEA, nº 10. 1989.

HÉBETTE, J. O grande Carajás: um novo momento da história moderna da Amazônia paraense. In: CASTRO, E. M. R. de; HÉBETTE, J. (orgs). Na Trilha dos Grandes 
Projetos: modernização e conflito na Amazônia. Cadernos do NAEA, $n^{\circ}$ 10. 1989. Belém: NAEA/UFPA. p. 7- 40.

A ocupação Humana Recente da Microrregião de Marabá. In: Cruzando a Fronteira: 30 anos de estudo sobre o campesinato na Amazônia. Vol IV. EDUFPA. Belém, PA, 2004. p. 63 - 71.

LEFEBVRE, H. La production de l'space. Paris: Anthropos, 1974.

GRAZIANO DA SILVA, J. O novo rural brasileiro. In: Revista Nova Economia, Belo Horizonte, v.7, $\mathrm{n}^{\circ}$ 1, p.43-81, 1997.

MAGALHÃES, S. B. Direitos e Projetos: uma leitura sobre a implantação de assentamentos no Sudeste do Pará. In: MARTINS, J. de S. Travessias: estudo de caso sobre a vivência da reforma agrária nos assentamentos. Porto Alegre: Editora da UFRGS, 2003. p. 247- 293.

MARAFON, G. J. Relações campo-cidade: uma leitura a partir do espaço rural fluminense. In: SAQUET, M.; SUZUKI, J.; MARAFON, G. Territorialidades e diversidade nos campos e nas cidades latino-americanas e francesas. São Paulo: Expressão Popular. 2011. p. 155-168.

MARQUES, M. I. M. O conceito de espaço rural em questão. Terra Livre. São Paulo, SP. n. 18, N. 19, p. 95-112, Jul./Dez, 2002.

MARX, M. Cidade no Brasil: terra de quem? São Paulo: Edusp/Ed. Nobel. 1991.

MEDEIROS, R. M. V. Dilemas na conceituação do campo e do rural no Brasil. In: SAQUET, M.; SUZUKI, J.; MARAFON, G. Territorialidades e diversidade nos campos e nas cidades latino-americanas e francesas. São Paulo: Expressão Popular. 2011. p. 59-66.

MICHELOTTI, F.; RIBEIRO, B.; SOUZA, H. de; FREITAS, R. L. de A. O agrário em questão: uma leitura sobre a criação dos Assentamentos Rurais no Sudeste do Pará. Encontro da Rede de Estudos Rurais, 2, 2007. Rio de Janeiro. Anais... Rio de Janeiro [s. n.], 2007.

QUEIROZ, M. I. P. de. Bairros Rurais Paulistas. Livraria Duas Cidades. São Paulo, SP. 1973.

O campesinato brasileiro: ensaios sobre civilização e grupos rústicos no Brasil. Petrópolis: Ed. Vozes. 2a Ed.1976. 242p.

REIS, Douglas Sathler dos. O Rural e o Urbano no Brasil. In: XV Encontro Nacional de Estudos Populacionais- ABE. Caxambu, MG. 2006.

SANTOS, M. (Org.). Território: Globalização e Fragmentação. São Paulo: HUTICEC, 2000. 
SARACENO, E. O conceito de ruralidade: problemas de definição em escala europeia. Programa de seminários Inea sobre desenvolvimento nas áreas rurais métodos de análise e políticas de intervenção. Roma, out. 1996/99.

SOARES, P. R. R. Dilemas da conceituação da cidade e do urbano no Brasil. In: SAQUET, M.; SUZUKI, J.; MARAFON, G. Territorialidades e diversidade nos campos e nas cidades latino-americanas e francesas. São Paulo: Expressão Popular. 2011. p. 67-78.

SOROKIN, P.; ZIMMERMAN, C.; GALPIN, C. Diferenças fundamentais entre o mundo rural e o urbano. In: MARTINS, J. de S. (Org.). Introdução crítica à sociologia rural. São Paulo: Hucitec, 1981.

SUZUKI, J. C. Campo e cidade no Brasil: transformações socioespaciais e dificuldades de conceituação. In: Revista NERA, Ano 10, № 10. Presidente Prudente, SP. 2007. p. 134-150.

VEIGA, J. E. da. A face rural do desenvolvimento: natureza, território e agricultura. Porto Alegre: Editora da UFRGS, 2000. 197p.

Cidades Imaginárias: o Brasil é menos urbano do que se calcula Campinas, SP. Autores Associados. 2 ed. 2003. 304 VELHO, O. G . Capitalismo Autoritário e Campesinato. Ed. DIFEL. São Paulo, SP. 1979.

WANDERLEY, M. de N. B. A ruralidade no Brasil moderno. Por un pacto social pelo desenvolvimento rural. In: CLACSO, Norma Giarracca. ¿Una nueva ruralidad en América Latina? Consejo Latinoamericano de Buenos Aires, Argentina. 2001. Disponível em: <http://bibliotecavirtual.clacso.org.ar/ar/libros/rural/wanderley.pdf>

Os Estudos Rurais no Brasil: as ciências sociais e as questões da sociedade [versão preliminar]. $33^{\circ}$ Encontro Anual da ANPOCS. Anais... Caxambu, SC. 2009a.

A emergência de uma nova ruralidade nas sociedades modernas avançadas: o "rural" como espaço singular e coletivo. In: O mundo rural como um espaço de vida. Reflexões sobre a propriedade da terra, agricultura familiar e ruralidade. Porto Alegre: Editora da UFRS, 2009b. p. 203 - 262.

Urbanização e Ruralidade: relações entre a pequena cidade e o mundo rural; estudo preliminar sobre os pequenos municípios em Pernambuco. In: O mundo rural como um espaço de vida. Reflexões sobre a propriedade da terra, agricultura familiar e ruralidade. Porto Alegre: Editora da UFRS, 2009c. p. 311- 328.

WOLF, E. Sociedades Camponesas. Rio de Janeiro: Ed. Zahar. 1976. $2^{\text {a Ed. }}$ 